Original Research

\title{
Grouting Reinforcement of Shallow and Small Clearance Tunnel
}

\author{
Mengtian Li ${ }^{1}$, Xiao Zhang ${ }^{1 *}$, Wei Kuang ${ }^{2}$, Zheng Zhou ${ }^{1}$ \\ 'Department of Geotechnical and Structural Engineering Research Center, Shandong University, China \\ ${ }_{2}^{2}$ Jinan Municipal Engineering Design \& Research Institute (group) CO.LTD., China
}

Received: 28 May 2020

Accepted: 8 September 2020

\begin{abstract}
In order to solve the problem that shallow and small clearance tunnels are easy to cause city road to collapse and chapped, taking the Jinan Yuhan Road Tunnel under typical geological conditions as the research object, the stability criterion of the middle soil wall is determined using a mechanical model of the tunnel middle wall. A grouting test under different loads of undisturbed soil in the tunnel is designed, and numerical simulation of the grouting of the middle wall of different tunnel depths and spacing is performed. The results show that the stability of the middle wall of the shallow and small clearance tunnel is related to depth, spacing, and the physical-mechanical properties of soil. The physical-mechanical properties of soil change little after grouting reinforcement with the same final grouting pressure as the burial depth increases. The stability criterion curve of the middle wall of Yuhan Road Tunnel is obtained by the measurement results of grouting test samples, and the numerical simulation results obtained by the experimental parameters have a high degree of agreement with the theoretical curve. Based on the stability criterion curve, sectional grouting was performed in Yuhan Road Tunnel, and the soil around the tunnel was successfully reinforced.
\end{abstract}

Keywords: tunnel depth, tunnel spacing, middle soil wall, stability criterion, grouting

\section{Introduction}

The separated tunnel structure is the most common form without being restricted by terrain. In actual projects, especially in the process of constructing urban shallow tunnels, the tunnels are often affected by topography, geological conditions, and tunnel routes. In this case, separated tunnel form cannot be used, and small clearance tunnels can effectively avoid this problem. Owing to the special structure of small clearance tunnels, the stress characteristics of

*e-mail: sduzhangxiao@sdu.edu.cn the middle wall are extremely complicated [1-3]. If the stress characteristics are not effectively handled, it is easy to cause disasters during the construction period, resulting in the loss of personnel and property and delays in the construction period $[4,5]$.

Compared with the general separated tunnels, the most important feature of the small clearance tunnels is the mutual influence $[6,7]$ between the left and right tunnels during the construction process, which is related to the spacing, depth, surrounding rock conditions, and excavation methods. Ghaboussi [8] performed a series of finite-element (FE) analyses to study the behaviour of a system of two parallel and adjacent tunnels. Kim [9] used reduced-scale model testing to study the effect of shield tunnel construction on the structural liners 
of existing nearby tunnels. Hefny [10] investigated the effect of new bored tunnels on the stresses induced in the lining of existing adjacent tunnels and studied the effects of the following tunnel properties in detail: the relative position, proximity, volume loss, buried depth, and lining thickness. Fu [11] presented an analytical solution for problems in determining displacements and stresses around deforming twin-parallel tunnels in an elastic half plane, on the basis of complex variable theory. Using the FLAC3D finite-difference code, Do $[12,13]$ made it possible to predict the impact between tunnels using full three-dimensional (3D) simulations, in which most of the elements of a mechanised tunnel process were modelled, as well as the influence of the lagging distance between the two mechanised tunnel faces. Zhang [14] simulated the ultimate and serviceability performances of underground twin rock caverns of various sizes and shapes. In this study, a 3D numerical investigation of the interaction between twin mechanised tunnels excavated in a horizontally parallel section was performed. Special attention was paid to the influence of the lagging distance between the two mechanised tunnel faces. Shalabi [15] investigated the interaction between adjacent tunnels excavated through soils in Saudi Arabia using FE analysis and examined the range of the soil properties. Liu [16] proposed an analytical solution to investigate the mechanical responses of an existing tunnel to new tunnel construction below without clearance.

The aforementioned research tasks are mainly based on the study of rocky highway tunnels, and there is a lack of related research on shallow buried soil tunnels in cities. The urban shallow buried earth tunnels are affected by the surrounding environment. During the construction period, its structural mechanical properties and deformation laws are complex, and the thickness of the middle wall is small. Its stability is the key to the design and construction of small clearance tunnels. The current reinforcement measures mainly involve bolt support. According to the analysis of the stress and deformation characteristics of the middle wall in the small clearance tunnel under the condition of no support, Yao [17] studied the influence of different surrounding rock levels, different supporting conditions, and different reinforcement measures on the stability of the small clearance tunnels. Wang [18] simulated the cross diaphragm method, double-heading construction method, arc-heading reservation core soil method, and benching tunnelling method and analysed the settlements of the vault and ground, level convergence, stress of the middle wall rock, and stability of the surrounding rock. In this study, the Yuhan Road Tunnel which has shallow burial depth and small spacing in the city of Jinan is taken as the research object. The effective reinforcement method of small clearance tunnels is investigated through theoretical analysis, model experiment, numerical simulation, and field test. The research results are applied to practical engineering.

\section{Theory}

For the small clearance tunnel, the key to the stability lies in the stability of the middle wall. The load on the middle wall in the tunnel can be simplified as the weight of the overlying rock mass between the two tunnel centre lines, as shown in Fig. 1. The assumptions are as follows. (1) The ground is horizontal, the soil is a continuous single medium, and the left and right holes are symmetrical. When the first hole is excavated, the rupture surface formed in the soil on both sides of the tunnel comprises two slopes which are at an angle of $\beta_{1}$ with the horizontal plane. (2) When the second hole is excavated, the soil on the outer side of the tunnel forms a slope with $\beta_{1}$, and the slope on the inside has angle $\beta_{2}$. The widths of the left and right holes are equal. The distance from the centre line of the hole to the middle wall is $b$, and the width of the middle wall is a. Analysis reveals that the load on the middle wall is also the load of the khaki portion of Fig. 1:

$$
P=\gamma h(a+2 b) L
$$

...where $\gamma$ is the average bulk density of the overburden, $h$ is the height of the overburden, and $L$ is the length of the middle wall.

The stress [19] on the middle wall is

$$
\sigma=\frac{\gamma h(a+2 b) L}{a L}=\frac{\gamma h(a+2 b)}{a}
$$

According to the theory of maximum normal stress in the classical theory of rock mass strength [20], when the following condition is satisfied, the structure is stable; otherwise, the structure is unstable:

$$
\sigma<[\sigma]
$$

...where $[\sigma]$ is the ultimate strength.

According to the Mohr-Coulomb criterion, the $[\sigma]$ expression can be obtained with the maximum principal stress $\sigma_{1}$ as the ordinate and the minimum principal stress $\sigma_{3}$ as the abscissa:

$$
[\sigma]=\sigma_{1}=\frac{2 c \cos \varphi}{1-\sin \varphi}+\frac{1+\sin \varphi}{1-\sin \varphi} \sigma_{3}
$$

...where $\mathrm{c}$ is the cohesion of the middle wall, and $\varphi$ is the internal friction angle of the middle wall. According to the literature [21], the lateral pressures on both sides of the middle wall of the small clearance tunnel are

$$
\left.\begin{array}{l}
\sigma_{3}=\lambda_{1} \gamma h_{i} \\
\sigma_{3}^{\prime}=\lambda_{2} \gamma h_{i}
\end{array}\right\}
$$




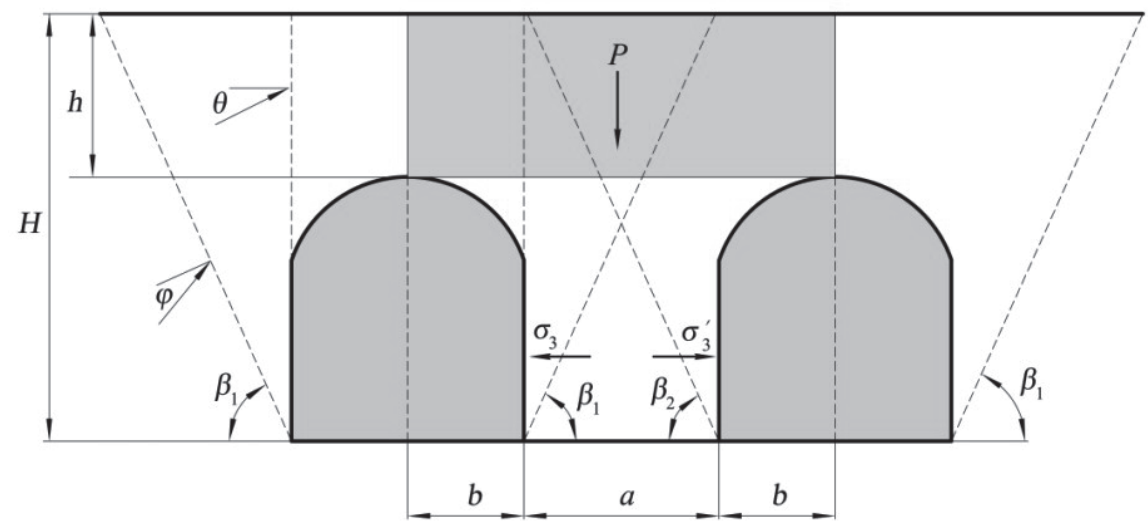

Fig. 1. Force model of middle wall.

...where $h_{i}$ is the buried depth when calculating the lateral stress, and the coefficients for the lateral pressure on both sides of the middle wall of the small clearance tunnel calculated in [19] are as follows.

$$
\begin{aligned}
& \lambda_{2}=\frac{\frac{b}{H}\left(1-\frac{b}{4 H} \tan \beta_{2}\right)\left(\tan \beta_{2}-\tan \varphi\right)}{1+\tan \beta_{2}(\tan \varphi-\tan \theta)+\tan \varphi \tan \theta} \\
& \lambda_{1}=\frac{\frac{b}{H}\left(1-\frac{b}{4 H} \tan \beta_{1}\right)\left(\tan \beta_{1}-\tan \varphi\right)}{1+\tan \beta_{1}(\tan \varphi-\tan \theta)+\tan \varphi \tan \theta}
\end{aligned}
$$

Here, $H$ is the buried depth, $\theta$ is the angle of the friction between the soil on both sides of the tunnel and the sinking body of the tunnel vault with respect to the horizontal plane, and the data can be found to be $\theta=0.5 \varphi$. After calculating $\tan \beta_{2}>\tan \beta_{1}, \lambda_{2}>\lambda_{1}$ and $\sigma_{3}^{\prime}>\sigma_{3}$ can be obtained; thus, $\sigma_{3}$ is the ultimate strength. $\beta_{1}$ can be obtained using the following formula:

$$
\tan \beta_{1}=\tan \varphi+\sqrt{\frac{(\tan \varphi+1) \tan \varphi}{\tan \varphi-\tan \theta}}
$$

Further, the damage discriminant of the middle wall of the tunnel during construction can be obtained:

$$
\frac{\gamma H(a+2 b)}{a}<\frac{2 c \cos \varphi}{1-\sin \varphi}+\frac{1+\sin \varphi}{1-\sin \varphi} \lambda_{1} \gamma H
$$

When this condition is met, the middle wall remains stable; otherwise, the middle wall is unstable. According to the above formula, for a certain project, the cohesion force $c$, the internal friction angle $\varphi$, and the heavy $\gamma$ of the middle wall can be adjusted via reinforcing measures to increase the stability of the middle wall. In this study, the effective reinforcement of the middle wall is implemented via the grouting method and applied to the Yuhan Road Tunnel project.

\section{Model Grouting Reinforcement Experiment}

\section{Undisturbed Soil Parameter Determination}

To judge the stability of the middle wall of the tunnel during construction, the undisturbed soil (Fig. 2) in the front, middle, and back sections of the Yuhan Road Tunnel was subjected to a geotechnical test. The moisture content (MC), $\rho$ (density), $c$ (cohesion), $\varphi$ (internal friction angle), $E$ (elasticity modulus), and $\mu$ (Poisson's ratio) of the soil samples were measured. The measurement results are presented in Table 1 .

\section{Grouting Experiment}

\section{Experiment System}

To obtain the parameters $\rho, c$, and $\varphi$ after grouting on the soil layer of different buried tunnels, grouting experiments with different loads were designed. The experimental system consists of a grouting container, a grouting pump, a grouting model, informationcollecting devices, etc., as shown in Fig. 3, which also shows the structure of the grouting model. The model cavity has an inner diameter of $184 \mathrm{~mm}$, a height of $400 \mathrm{~mm}$, and an effective filling height of $380 \mathrm{~mm}$.

The lower end of the model cavity is closed by a permeable piston, and a hydraulic jack transmits

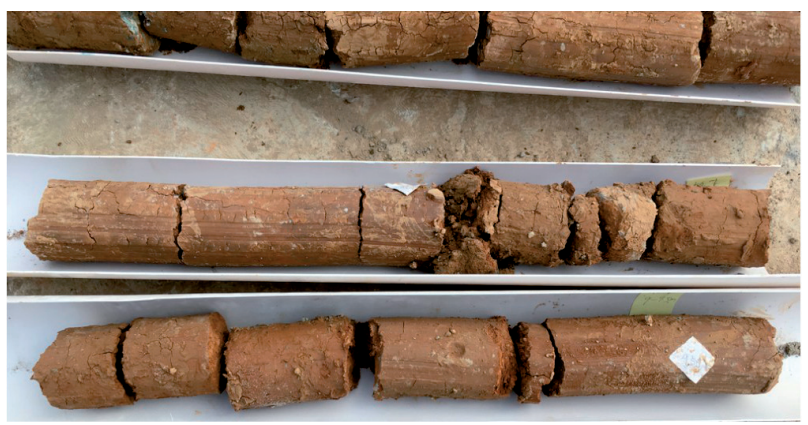

Fig. 2. Undisturbed soil samples from three sections. 
Table 1. Determination of the physical properties of undisturbed soil.

\begin{tabular}{|c|c|c|c|}
\hline \multirow{2}{*}{$\begin{array}{c}\text { Determination } \\
\text { items }\end{array}$} & \multicolumn{3}{|c|}{ Determination result } \\
\cline { 2 - 4 } & $\begin{array}{c}\text { Front } \\
\text { sample }\end{array}$ & $\begin{array}{c}\text { Middle } \\
\text { sample }\end{array}$ & $\begin{array}{c}\text { Back } \\
\text { sample }\end{array}$ \\
\hline $\mathrm{MC}(\%)$ & 19.35 & 21.47 & 20.38 \\
\hline $\mathrm{P}\left(\mathrm{g} / \mathrm{cm}^{3}\right)$ & 1.603 & 1.712 & 1.735 \\
\hline $\mathrm{C}(\mathrm{kPa})$ & 69.885 & 69.137 & 74.544 \\
\hline$\Phi\left({ }^{\circ}\right)$ & 24.91 & 22 & 19.09 \\
\hline $\mathrm{E}$ & 15.19 & 14.65 & 14.37 \\
\hline$\mu$ & 0.39 & 0.4 & 0.43 \\
\hline
\end{tabular}

pressure to the permeable piston through an extension bar. A pressure sensor is positioned between the jack and the extension bar. The information-collecting devices can observe and collect experimental data, such as the jack pressure, grouting pressure, and soil pressure. Four CJLY-350 miniature soil pressure sensors $(28 \mathrm{~mm} \times 9 \mathrm{~mm})$ are symmetrically and vertically placed $50 \mathrm{~mm}$ from the top of the cavity using external fixing bolts. The transmission lines of the sensors are connected to the XL2101G static strain gauge through a full bridge connection by a seal joint mounted on the cavity wall hole.

\section{Experimental Design}

The soil sample collected in the middle section was selected as the experimental soil sample. To simulate the grouting reinforcement for three different depths $(10,20$, and $30 \mathrm{~m})$, three pressures were applied by the jack, and the values displayed by the soil pressure sensor were 147, 295, and $442 \mathrm{kPa}$, respectively. The grouting materials used in the experiment were a cement-water glass double-liquid slurry and a cement
Table 2. Grouting experiment arrangement.

\begin{tabular}{|c|c|c|c|}
\hline $\begin{array}{c}\text { Experiment } \\
\text { number }\end{array}$ & $\begin{array}{c}\text { Soil pressure } \\
/ \mathrm{kPa}\end{array}$ & Grout type & $\begin{array}{c}\text { Number of } \\
\text { times }\end{array}$ \\
\hline $\mathrm{I}-1$ & 147 & $\mathrm{~S}_{1}$ & 5 \\
\hline $\mathrm{I}-2$ & 295 & $\mathrm{~S}_{2}$ & 5 \\
\hline $\mathrm{I}-3$ & 442 & $\mathrm{~S}_{1}$ & 5 \\
\hline $\mathrm{I}-4$ & 147 & $\mathrm{~S}_{2}$ & 5 \\
\hline $\mathrm{I}-5$ & 295 & $\mathrm{~S}_{1}$ & 5 \\
\hline $\mathrm{I}-6$ & 442 & $\mathrm{~S}_{2}$ & 5 \\
\hline
\end{tabular}

single-liquid slurry. The cement was P.O. 32.5 ordinary Portland cement, and the water glass was a solution with a modulus of 3.2 and a concentration of $1.17 \mathrm{~mol} / \mathrm{L}$. A manual grouting pump was used to uniformly inject the slurry into the grouting mold through a two-liquid mixer above the grouting model. A double slurry with a watercement ratio of 0.8 and a slurry-to-water glass volume ratio of $1: 1$, as well as a single slurry with a watercement ratio of 1:1, were used, which were labelled as $\mathrm{S}_{1}$ and $S_{2}$, respectively. Using these two types of slurries, six groups of grouting tests were performed under soil pressures of $147.29,294.59$, and $441.88 \mathrm{kPa}$. When the grouting pressure reached $2 \mathrm{MPa}$, the grouting was completed, and each set of experiments was performed five times, as shown in Table 2. When the grouting was finished, the remolded soil was subjected to moldremoval treatment after placing the grouting mold for 30 mins, and the physical and mechanical parameters of the samples were measured after 3 days of maintenance.

\section{Grouting Experiment Results}

\section{Pressure Fluctuation Analysis}

The curves for the grouting pressure and grouting additional stress with respect to time in experiments
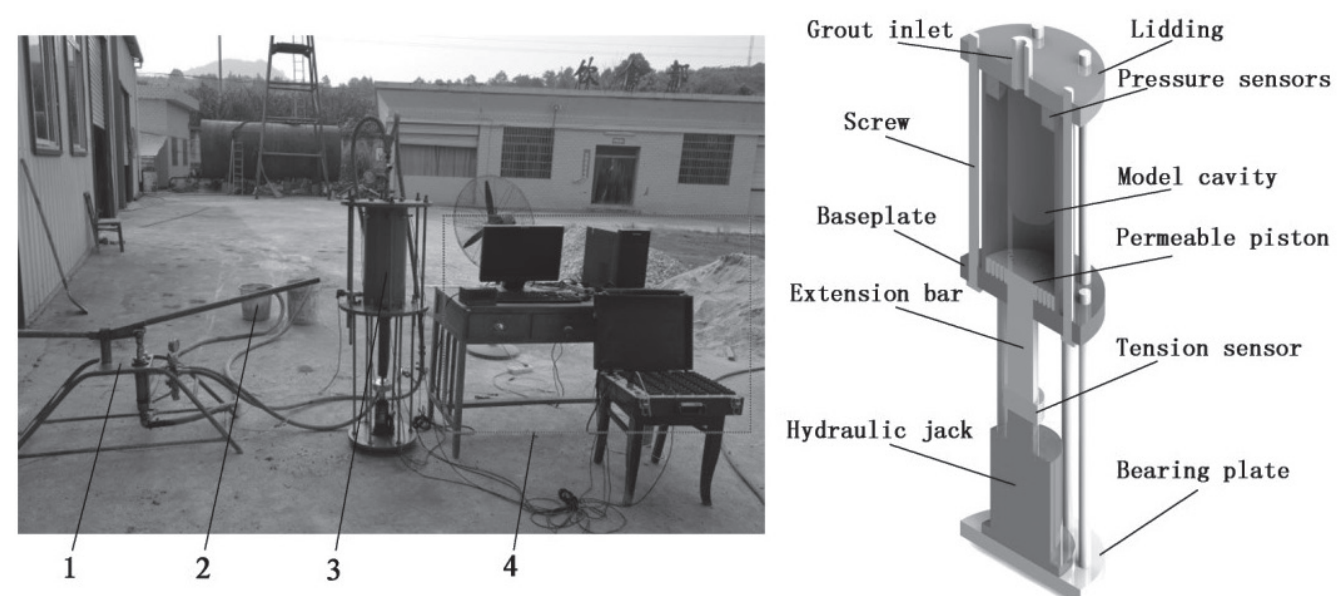

Fig. 3. Experimental system

1 Grouting pump, 2 grouting container, 3 grouting model, 4 information-collecting devices 


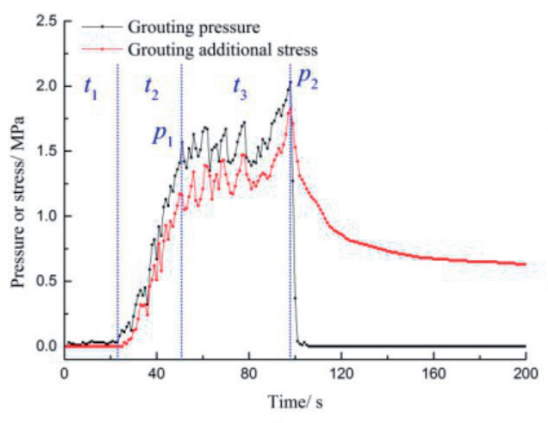

I-1

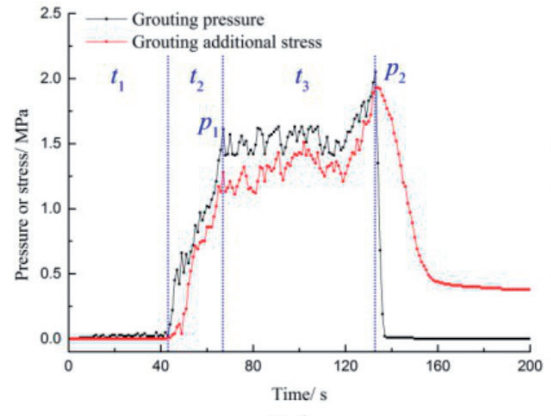

I-4

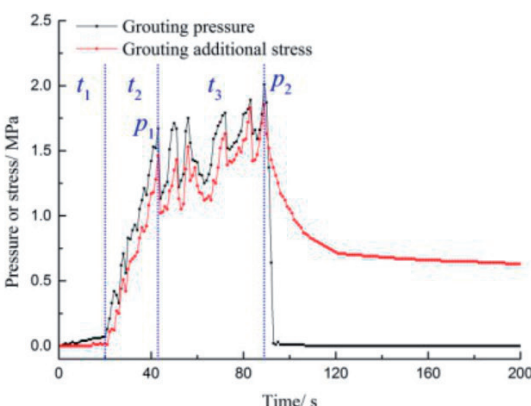

I-2

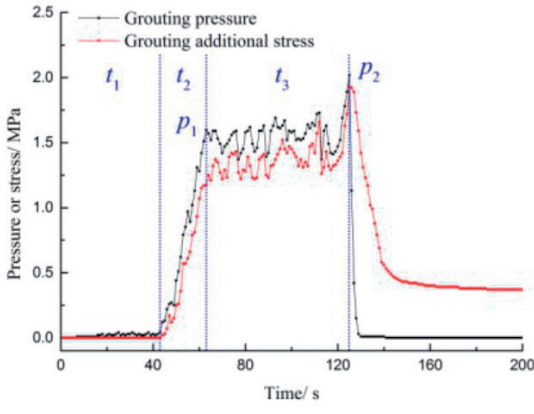

I-5

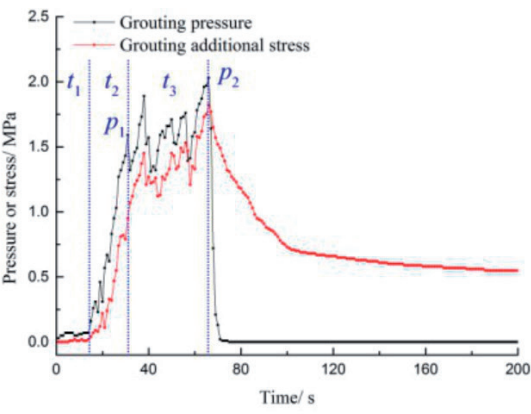

I-3

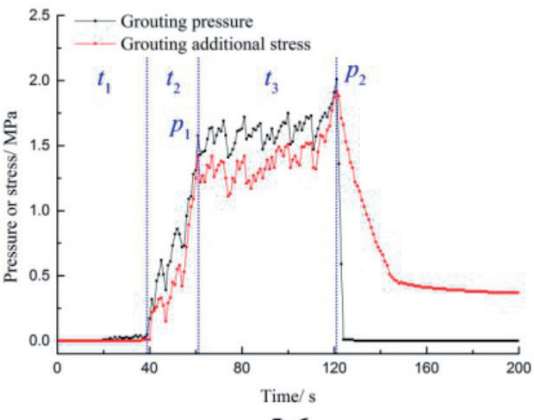

I-6

Fig. 4. Curves for the grouting pressure and additional stress.

I-1 to I-6 are shown in Fig. 4. The additional stress of grouting refers to the ratio of $F$ (grouting load and selfweight of the grout) to $A$ (area of the permeable piston) and is denoted as $p_{1}$, that is, $p_{1}=F / A$.

As shown in Fig. 4, the pressure in grouting experiment I-1 is basically unchanged from 0-24 s. This stage is the slurry filling stage, in which the slurry spreads to the gaps. The grouting pressure increases rapidly to $1.57 \mathrm{MPa}$ from $25-51 \mathrm{~s}$, and the slurry begins to compact the soil near the grouting port, which is the stage of compaction grouting. At $52 \mathrm{~s}$, the slurry splits the soil to form a split channel and expands rapidly, and the grouting pressure decreases rapidly. Subsequently, multiple subsequent splitting occurs; thus, the grouting pressure continues to fluctuate up and down from $52-98 \mathrm{~s}$, reaching a final pressure of $2.03 \mathrm{MPa}$, at which the grouting stops. The other five groups of experiments yield the same behaviour; thus, characteristic data during the grouting process, such as $t_{1}$ (the slurry filling time period), $t_{2}$ (the compaction grouting time period), $t_{3}$ (the split grouting time period), $p_{1}$ (the maximum pressure value of the compact grouting), and $p_{2}$ (the final grouting pressure), can be obtained, as shown in Table 3 .

The data variation law in Table 3 is analysed: as the applied load increases, the slurry filling phase time decreases significantly, owing to the decrease of the pore volume of the soil under a larger confining pressure. With the increase of the applied load, the time to reach the final pressure decreases, indicating that the amount of grouting of the shallow buried layer decreases with the increase of the buried depth, but the reduction is small. When the grouting pressure rapidly increases to approximately $1.6 \mathrm{MPa}$, the pressure begins to fluctuate, indicating that the split pressure is approximately $1.6 \mathrm{MPa}$ in the range of $20-40 \mathrm{~m}$ in the stratum. Experiments I-1, I-2, and I-3 have a shorter time to reach $p_{1}$ and $p_{2}$ than $\mathrm{I}-4, \mathrm{I}-5$, and $\mathrm{I}-6$, indicating that the two-liquid grouting efficiency is higher.

The additional stress of grouting is due to the grouting pressure acting on the soil during the grouting process, which causes deformation and changes the strength of the medium. In the grouting process, the additional stress variation law in the six groups of experiments is basically consistent with the grouting pressure change law, but the values are lower than the grouting pressure. After the end of the grouting, the grouting pressure disappears, but the additional stress is slowly attenuated until becoming stable. The grouting pressure must overcome the resistance and the viscous force of the slurry during the transfer process, and the total stress in the soil is actually lower than the grouting pressure. The total stress includes the pore water pressure; thus, the grouting additional stress that

Table 3. Characteristic data of the grouting process.

\begin{tabular}{|c|c|c|c|c|c|}
\hline & $t_{1} / \mathrm{s}$ & $t_{2} / \mathrm{s}$ & $t_{3} / \mathrm{s}$ & $p_{1} / \mathrm{MPa}$ & $p_{2} / \mathrm{MPa}$ \\
\hline $\mathrm{I}-1$ & $0-24$ & $25-51$ & $52-98$ & 1.57 & 2.03 \\
\hline $\mathrm{I}-2$ & $0-20$ & $21-43$ & $44-89$ & 1.67 & 2.01 \\
\hline $\mathrm{I}-3$ & $0-14$ & $15-31$ & $32-66$ & 1.59 & 2.03 \\
\hline $\mathrm{I}-4$ & $0-43$ & $44-67$ & $68-133$ & 1.61 & 2.05 \\
\hline $\mathrm{I}-5$ & $0-41$ & $42-63$ & $64-125$ & 1.60 & 2.02 \\
\hline $\mathrm{I}-6$ & $0-39$ & $40-61$ & $62-121$ & 1.58 & 2.01 \\
\hline
\end{tabular}




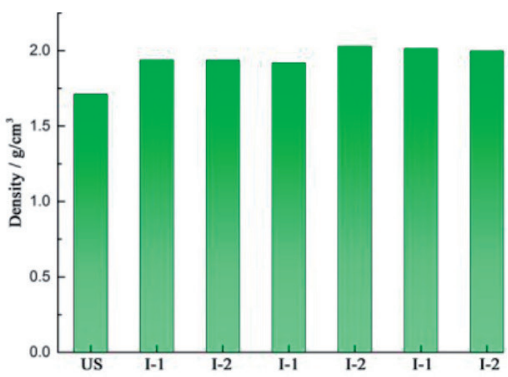

(a)

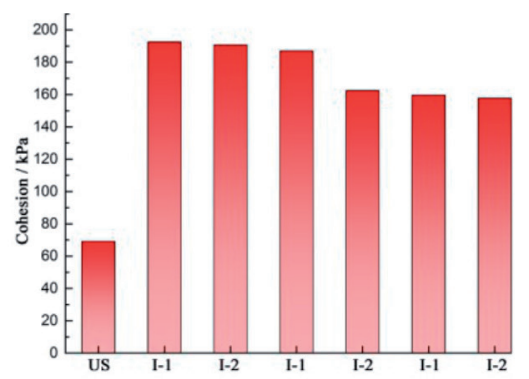

(b)

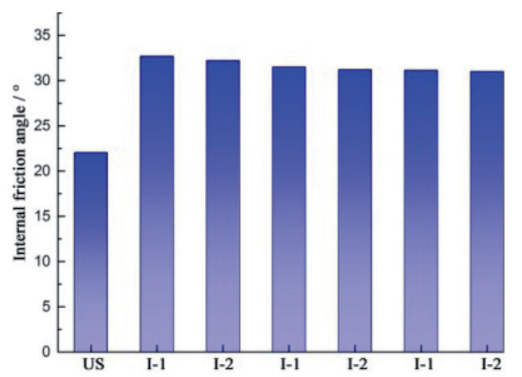

(c)

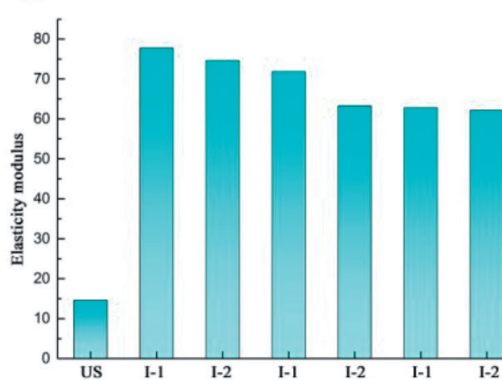

(d)

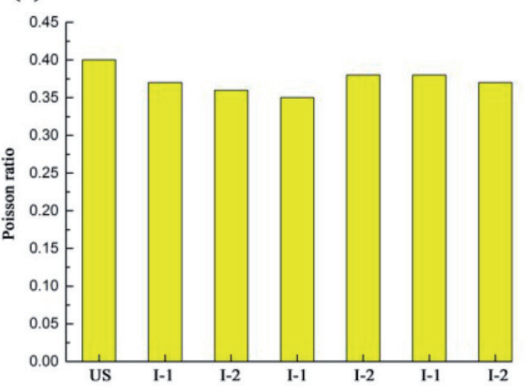

(e)

Fig. 5. Comparison of soil properties.

causes the deformation and strength of the medium to change is significantly lower than the grouting pressure.

\section{Determination of Physical Parameters of Remolded Soil}

The samples of remolded soil after $3 \mathrm{~d}$ of curing after grouting are subjected to direct shearing and uniaxial compression tests, and the $\rho, c, \varphi, E$, and $\mu$ of the soil are measured, as shown in Fig. 5. The figure indicates that after grouting reinforcement, the $\rho, c, \varphi$, and $E$ of the experimental soil are significantly increased, and the $\mu$ is reduced. The final density of the soil grouted with slurry $\mathrm{S}_{1}$ is lower than that of $\mathrm{S}_{2}$, indicating that the amount of $S_{1}$ is smaller when the final pressure of grouting is reached, and after grouting with $\mathrm{S}_{1}$, the $c, \varphi$, and $E$ of the soil are significantly larger than $\mathrm{S}_{2}$, and the Poisson's ratio is smaller. With the increase of the soil external pressure, the $\rho, c, \varphi$, and $E$ of the soil are reduced, and the $\mu$ is increased, but the change is not significant. These results show that the reinforcing effect of the slurry $\mathrm{S}_{1}$ is significantly better than that of the slurry $\mathrm{S}_{2}$, and the amount of slurry needed is smaller.

\section{Numerical Simulation of Grouting Reinforcement of Small Clearance Tunnel}

\section{Calculation Model}

The COMSOL software was used to numerically simulate the deformation of the middle wall and surrounding rock of the small clearance tunnel. The model size was $100 \mathrm{~m} \times 80 \mathrm{~m} \times 100 \mathrm{~m}$, and Fig. 6 shows the model meshing. The effects of the buried depth and spacing on the stability of the tunnel middle wall were investigated for 10 different working conditions, as shown in Table 4. The surrounding rock was soil, and the elastoplastic model was employed. The bottom was a fixed constraint, the boundary on both sides was a sliding constraint, the upper part was a free boundary, and the load on the model was the self-heavy stress of the overlying stratum in the upper part of the tunnel. The maximum span of the tunnel was $10 \mathrm{~m}$, and the height from the vault to the invert arch was $10 \mathrm{~m}$. The settlement of the vault, horizontal convergence displacement, and plastic zone change after the grouting reinforcement of the tunnel middle wall under different working conditions were examined. The monitoring points are indicated by the red dots in Fig. 6. According to the results of the soil property

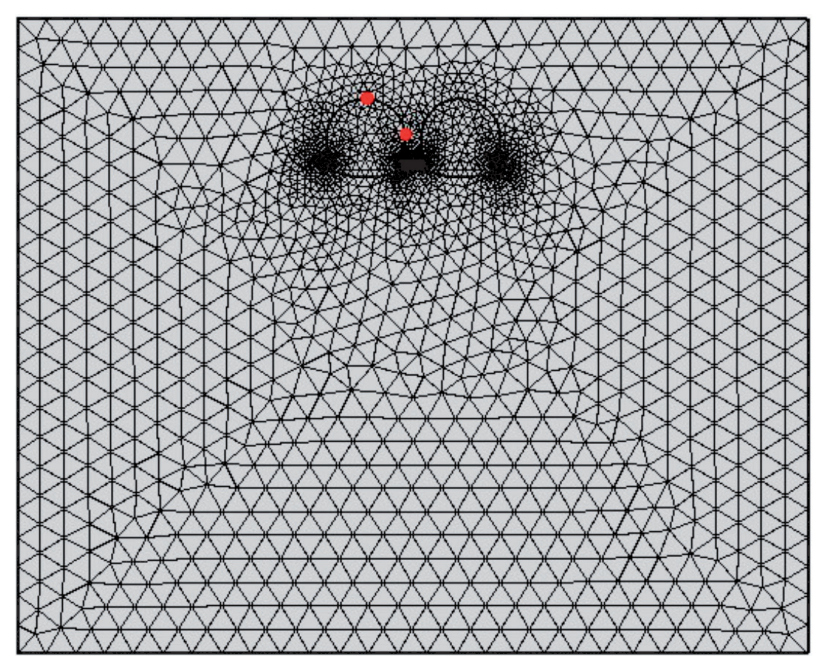

Fig. 6. Mesh generation. 
Table 4. Conditions of the numerical simulation.

\begin{tabular}{|c|c|c|}
\hline Number & Spacing / $\mathrm{m}$ & Buried depth / m \\
\hline 1 & \multirow{3}{*}{2} & 20 \\
\hline 2 & & 30 \\
\hline 3 & & 40 \\
\hline 4 & \multirow{3}{*}{5} & 20 \\
\hline 5 & & 30 \\
\hline 6 & & 40 \\
\hline 7 & \multirow{3}{*}{10} & 20 \\
\hline 8 & & 30 \\
\hline 9 & & 40 \\
\hline 10 & \multirow{3}{*}{20} & 20 \\
\hline 11 & & 30 \\
\hline 12 & & 40 \\
\hline
\end{tabular}

Table 5. Values of the soil parameters.

\begin{tabular}{|c|c|c|}
\hline Measurement item & Before grouting & After grouting \\
\hline $\mathrm{P}\left(\mathrm{g} / \mathrm{cm}^{3}\right)$ & 1.712 & 1.931 \\
\hline$C(\mathrm{kPa})$ & 69.137 & 190.13 \\
\hline$\Phi\left({ }^{\circ}\right)$ & 22.07 & 32.15 \\
\hline$E$ & 14.65 & 74.75 \\
\hline$\mu$ & 0.4 & 0.36 \\
\hline
\end{tabular}

test after grouting under different conditions, as shown in Fig. 5, the influence of the soil pressure on various performance parameters was small. The parameters of the undisturbed soil and the average value of the soil parameters under various soil pressures were taken as the model parameters before and after the grouting in the numerical simulation, as shown in Table 5.

\section{Numerical Simulation Results}

Fig. 7 shows the results of the vault settlement and horizontal convergence of the tunnel calculated at the monitoring point. The tunnel settlement and horizontal convergence of the same buried depth tunnel gradually decrease with the increase of the spacing, and the tunnel settlement and horizontal convergence of the same spacing tunnel gradually decrease with the increase of the buried depth. After grouting reinforcement, the vault settlement and horizontal convergence for various working conditions are reduced to some extent.

When the tunnel spacing is too small, the middle wall between the two tunnels completely enters the plastic state, and the plastic zone of the two tunnels connect. At this time, the tunnel is prone to overall damage, and reinforcement measures must be taken to ensure the stability of the tunnel. At the same buried depth, as the range of the plastic zone decreases with the decrease of the spacing, the plastic zone between the two tunnels gradually separates. Fig. 8 shows the plastic-zone distribution for different spacings at the depth of $30 \mathrm{~m}$.

The calculation results for the plastic area before reinforcement are shown in Fig. 9. At a depth of $20 \mathrm{~m}$, the plastic area of the middle wall of the tunnel is connected when the spacing is $<5 \mathrm{~m}$, and it is not connected when the spacing is $>10 \mathrm{~m}$; that is, the stability of the middle wall is poor when the net distance is $<5 \mathrm{~m}$. At the depth of $30 \mathrm{~m}$, whether connection of the plastic zone of the two tunnels occurs between 10 and $20 \mathrm{~m}$, and at the depth of $40 \mathrm{~m}$, the connectivity of the plastic area of the middle wall in the tunnel also occurs between 10 and $20 \mathrm{~m}$.

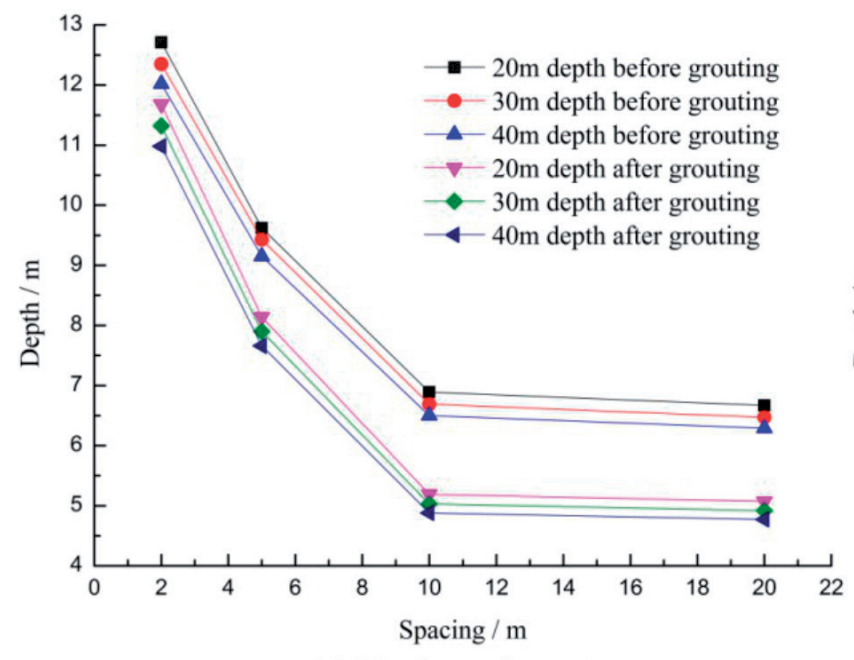

(a) Vault settlement

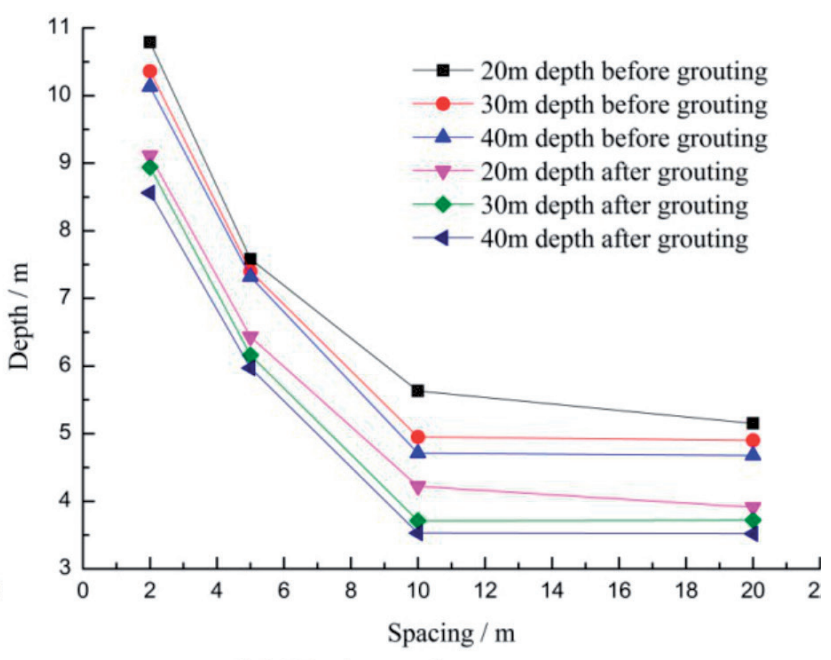

(b) Horizontal convergence

Fig. 7. Vault settlement and horizontal convergence of the tunnel. 

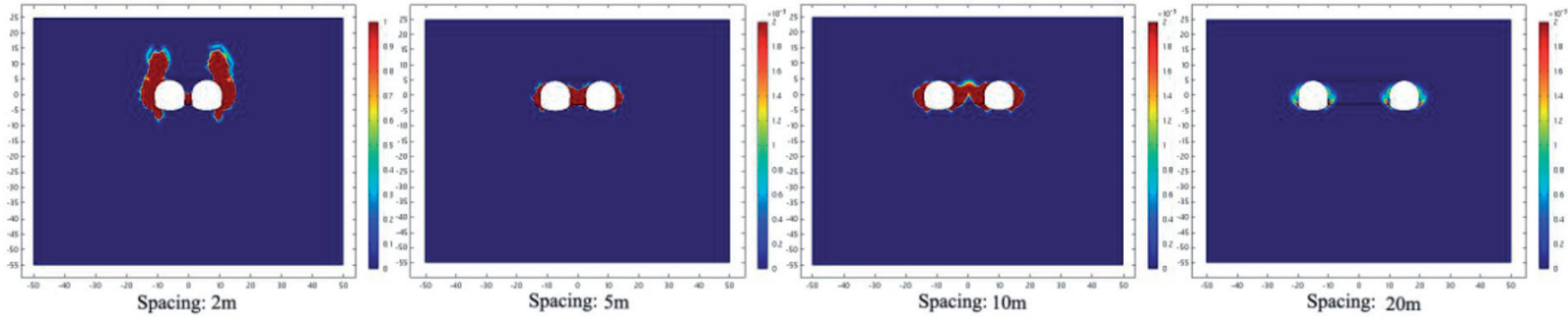

Fig. 8. Distribution of the plastic zone at 30-m depth.

The plastic-zone distribution after grouting reinforcement is shown in Fig. 10. When the buried depth is $20 \mathrm{~m}$ and the minimum spacing is $5 \mathrm{~m}$, the plastic zone of the middle wall of the tunnel after reinforcement is not connected. The same situation occurs at a buried depth of $30 \mathrm{~m}$ and minimum spacing of $5 \mathrm{~m}$, as well as a buried depth of $40 \mathrm{~m}$ and minimum spacing of $10 \mathrm{~m}$. These results show that the stability of the middle wall is significantly improved after grouting reinforcement.
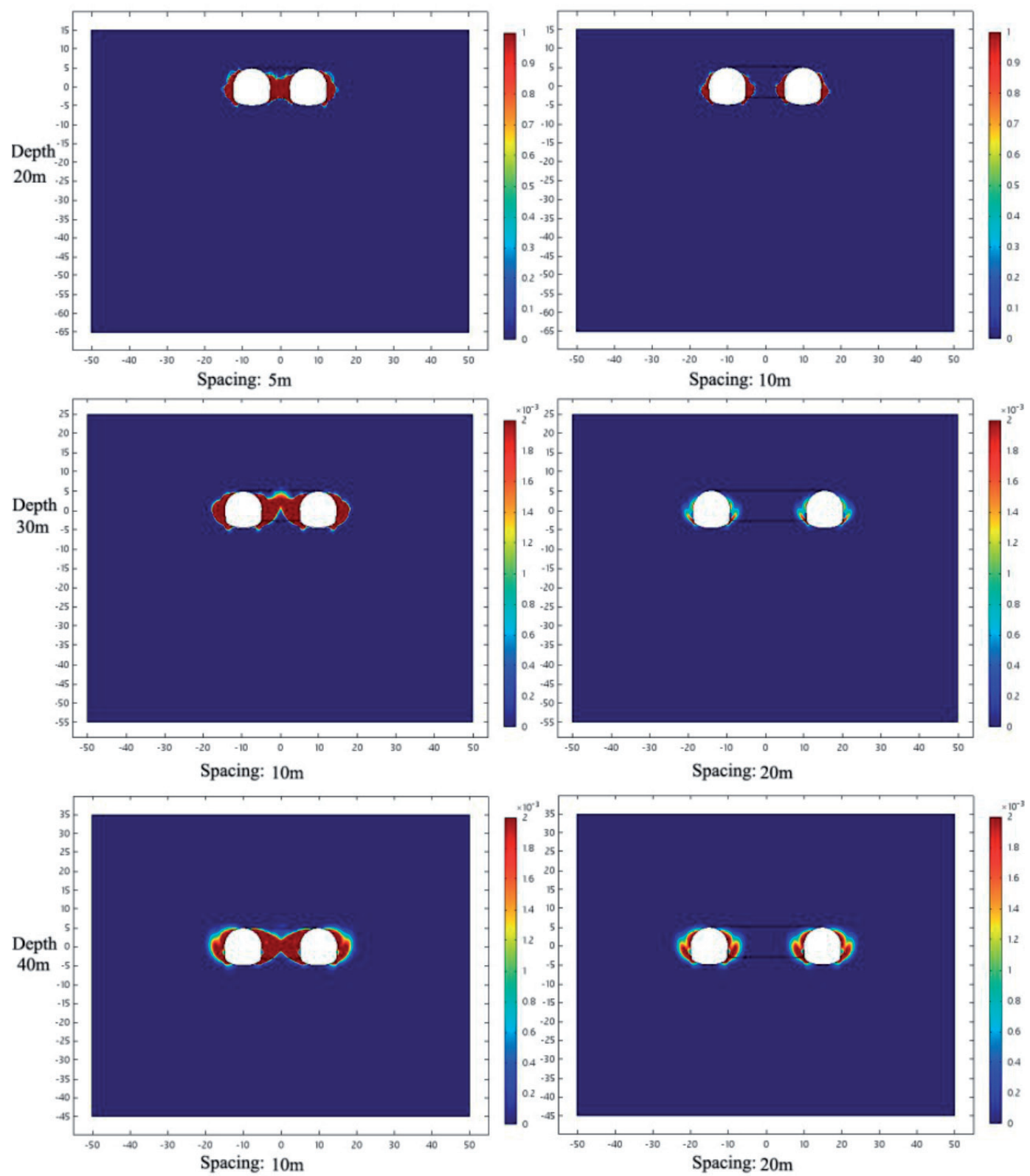

Fig. 9. Connectivity of plastic areas with different depths before reinforcement. 

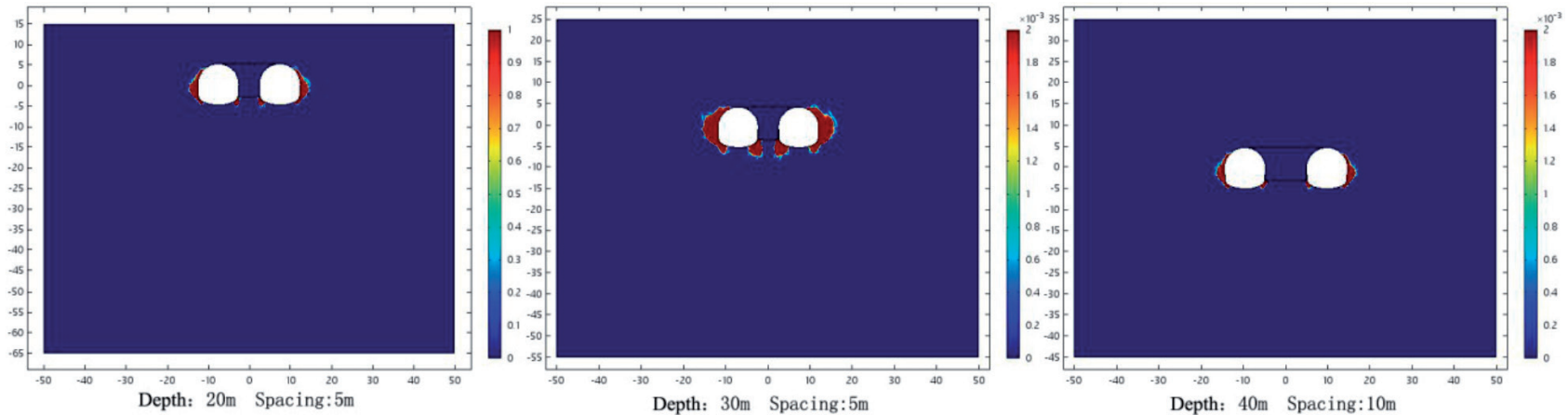

Fig. 10. Connectivity of plastic areas with different buried depths after reinforcement.

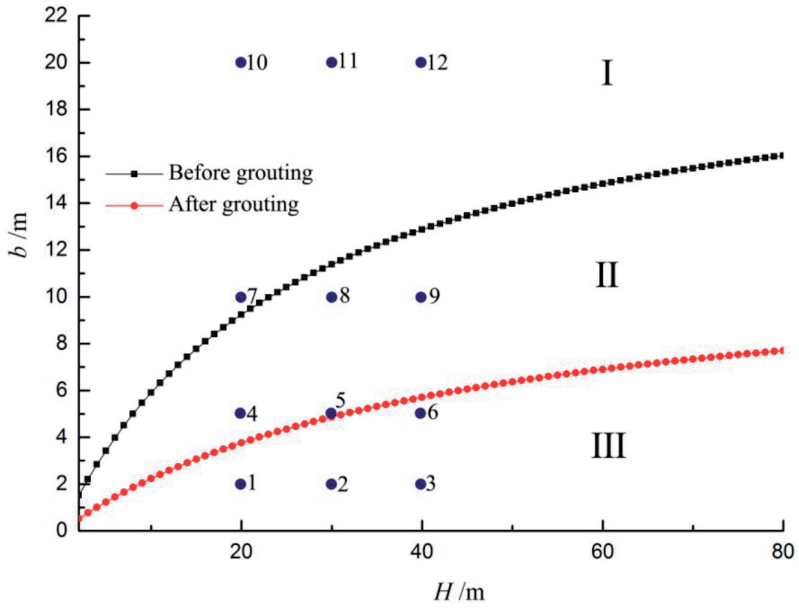

Fig. 11. Stability judgment curve.

According to the measured data in Table 5 and Formula (8), the curve of the minimum spacing a with the buried depth $H$ in the small clearance tunnel before and after grouting can be plotted as shown in Fig. 11, which is also the stability judgment curve.
For the convenience of calculation, the lateral pressure coefficient is reduced to $\lambda=\mu /(1-\mu)$, with values of 0.667 and 0.563 before and after reinforcement, respectively. Area $I$ in Fig. 11 is the range of the spacing and the buried depth when the middle wall is stabilised before grouting, and area II is the range of the spacing and the buried depth when the middle wall is unstable before grouting and when the middle wall is stabilised after grouting. Area III is the range of the spacing and depth of the middle wall when the grouting is unstable. In Fig. 11, the stability of working conditions 1-12 can be judged, which is consistent with the numerical simulation results.

\section{Application of Middle Wall Grouting Reinforcement in Yuhan Road Tunnel}

The Yuhan Road Tunnel is connected to the Hero Mountain Road Viaduct, with a total length of $3.7 \mathrm{~km}$. Exploration reveals that the underlying strata of this project are quaternary strata - mostly wet loess, viscous soil, and gravel soil caused by filling soil and slope alluvium - and underlying Ordovician limestone. The filling soil is the main component of the overlying
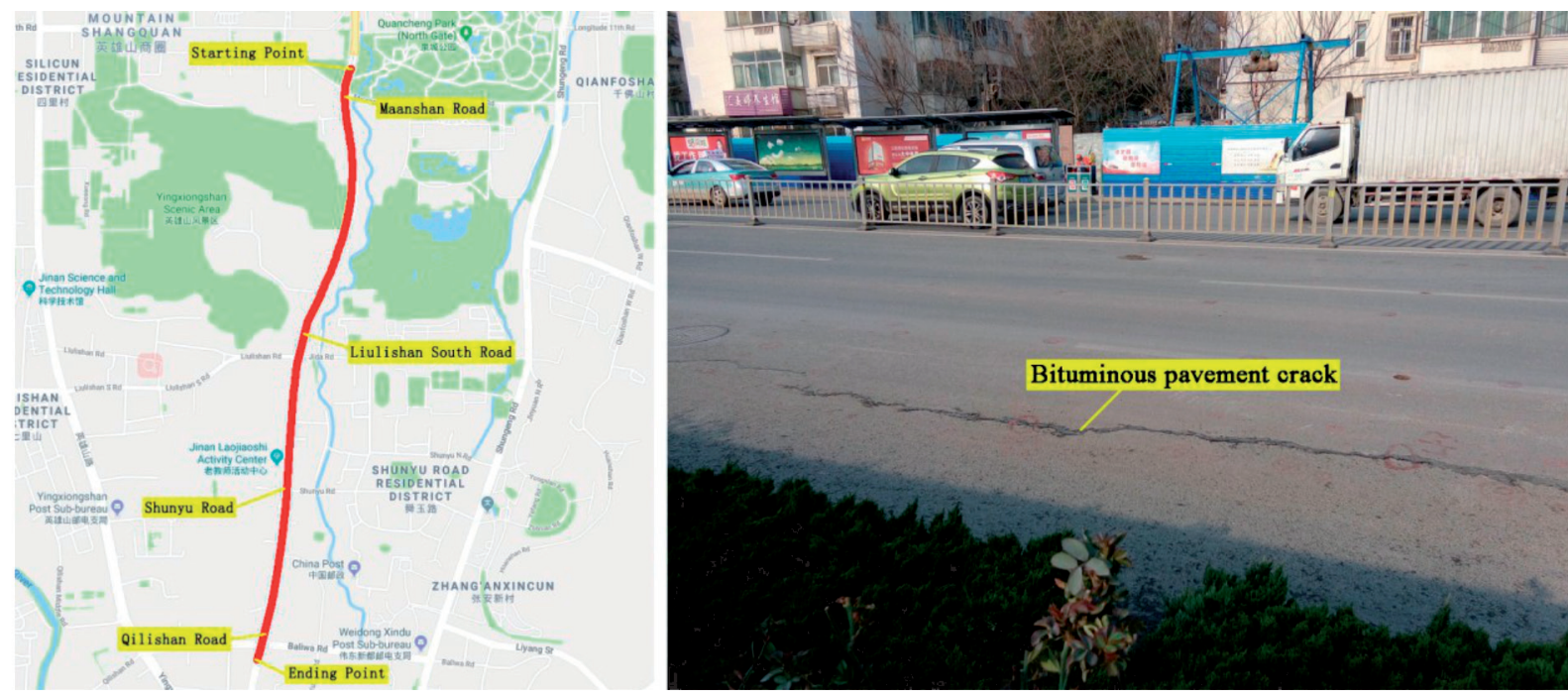

Fig. 12. Yufu Road section and the cracking scene. 

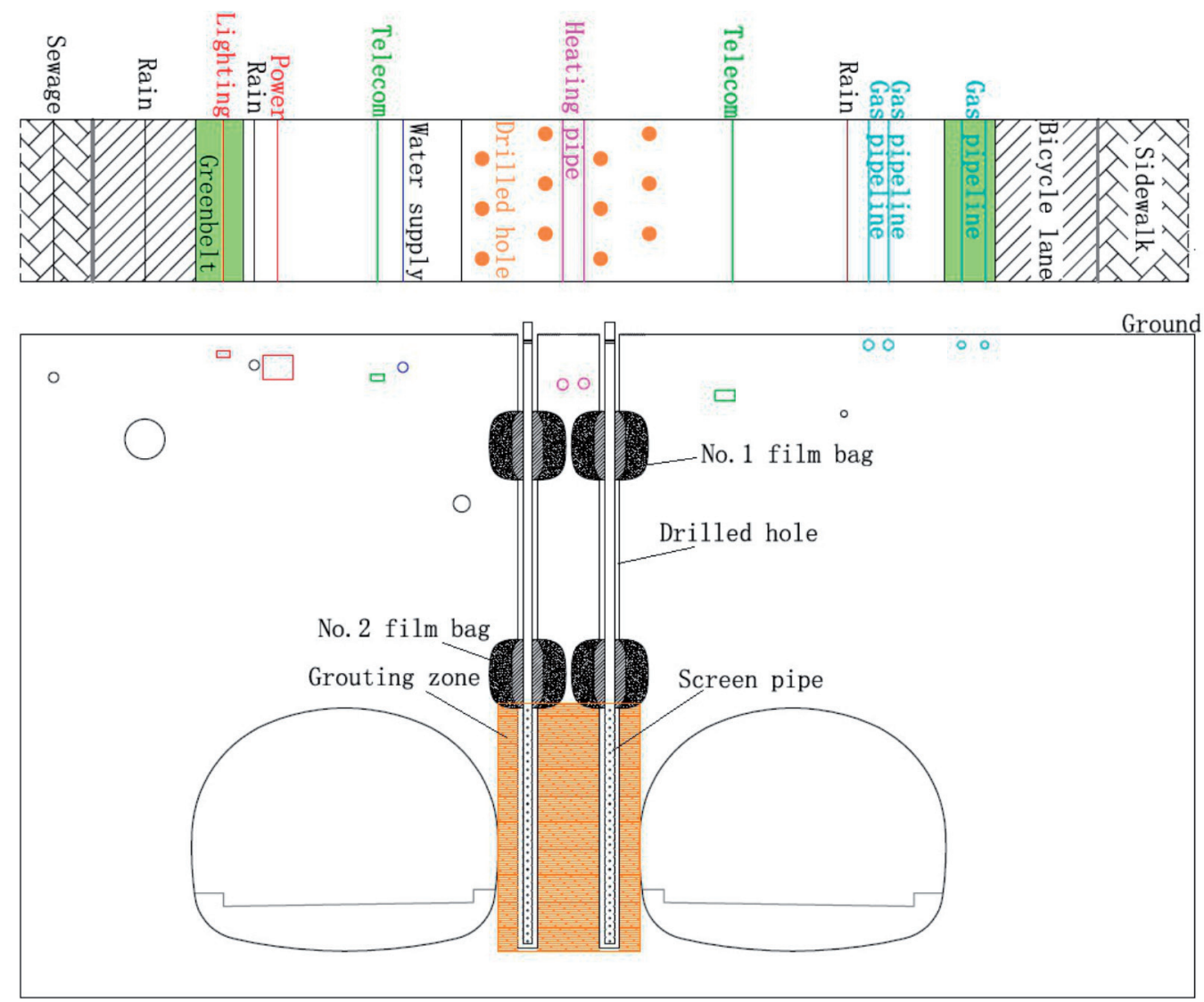

Fig. 13. Construction scheme.

surrounding rock, and this part is mainly composed of loess and cohesive soil. The soil quality is relatively uniform, and the bearing capacity is poor. This part is the main working area of the grouting reinforcement project. The buried depth of the tunnel is between 18 and $20 \mathrm{~m}$, and the structure adopts a small clearance tunnel. During the construction of the underground tunnel, the overlying surrounding rock was greatly deformed and subsided. The surface of Yuhan Road was seriously cracked, which affected the normal excavation of the underground tunnel and the normal traffic of vehicles, as shown in Fig. 12.
To ensure the successful excavation of the tunnel, according to the test and numerical simulation of the grouting reinforcement of the shallow buried and small clearance tunnel, surface drilling and vertical grouting were applied to the middle wall along the tunnel. According to the criterion of the stability of the middle wall before and after grouting in Fig. 11, the grouting reinforcement section was set, and the section with larger spacing was only used for simple support treatment. Owing to the complexity of the underground pipelines along the line, as shown in Fig. 13, four rows of boreholes and grouting pipes were laid along the

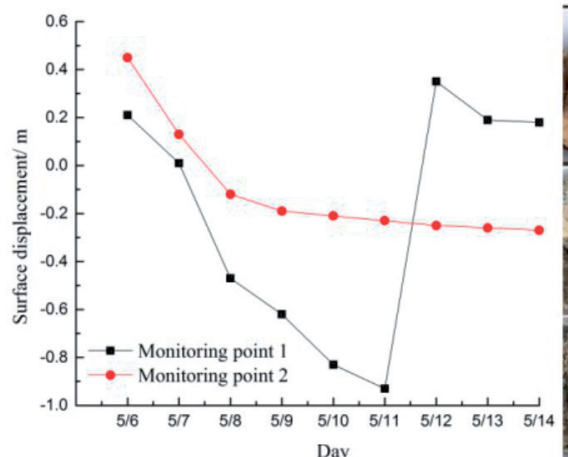

(a)

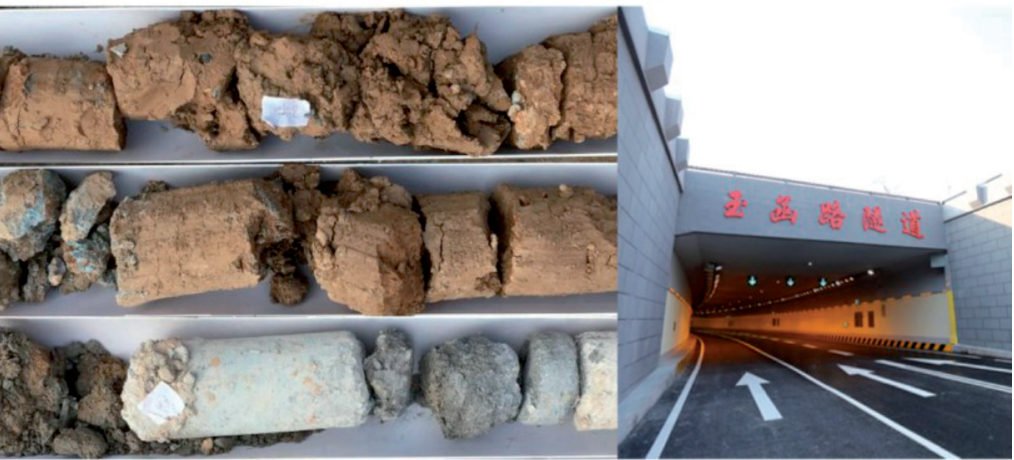

(b) (c)

Fig. 14. Project monitoring and the completed tunnel. 
line to avoid surface road obstacles and underground pipelines. In the middle wall area, the screen pipe grouting method was employed, and a two-stage film bag was used to prevent slurry leakage. The final pressure of the grouting was set as $2 \mathrm{MPa}$.

After the grouting was finished, grouting effect analysis methods - such as surface displacement monitoring and measurement, excavation and exposure of the slurry vein, and core sample detection - were used to verify the reinforcement of the surrounding rock and the control of the surface uplift. Fig. 14a) shows the displacement over time of the two surface measurement points in the reinforcement section and the non-reinforcement section. The tunnel excavation at measurement point 1 causes settlement on the surface. When the settlement area is pre-reinforced and grouted, the surface of the reinforcement area rises rapidly. After the grouting, the surface displacement changes tend to be stable. The spacing at measurement point 2 is in area I of Fig. 11, and the middle wall in the tunnel is stable. It can be found from Fig. 14a) that the change of the surface displacement caused by excavation is small; thus, no grouting reinforcement is needed. Fig. 14b) shows the core of the tunnel grouting reinforcement inspection hole. The slurry in the reinforcement zone is well-diffused, and the final Yuhan Road Tunnel is smoothly penetrated, as shown in Fig. 14c).

\section{Conclusions}

A mechanical model for a shallow buried tunnel with small spacing was established, and the stability criterion of the middle wall was obtained according to the physical and mechanical properties of the soil stratum. According to this criterion, the depth and spacing of the tunnel for ensuring the stability of the middle wall under specific soil properties were obtained.

A grouting experiment for the soil layer with different depths was designed, and the physicomechanical parameters of the soil layer before and after grouting in the Yuhan Road Tunnel were obtained, along with the stability judgment curves for the middle wall of the small-space tunnel of Yuhan Road before and after grouting.

A numerical simulation of the stability of the middle wall of the small clearance tunnel was performed by using the physico-mechanical parameters of the soil layer in the Yuhan Road Tunnel. The simulation results agreed well with the obtained stability judgment curve.

Taking the stability judgment curves before and after grouting in the middle wall of Yuhan Road Tunnel as a guide, the Yuzhong Road tunnel was grouted in sections. Monitoring revealed that the reinforcement effect was good, and the tunnel was finally completed successfully.

\section{Acknowledgements}

This work was supported by the National Natural Science Foundation of China (grant no. 52009072) and Science and Technology Project of Shandong High-Speed Group Co., Ltd. (SDGS-KJCX-2020-006/ Bid Section 5 Key technology and effect evaluation method of grouting control for complex rock and soil mass).

\section{Conflict of Interest}

The authors declare no conflict of interest.

\section{References}

1. RANTAN R., PRAKASH K., ASHUTOSH K., SINGH T.N. Numerical analysis of surface subsidence in asymmetric parallel highway tunnels. Journal of Rock Mechanics and Geotechnical Engineering, 9 (1), 170, 2017.

2. FADI H., ISAM S. Numerical analysis of the interaction between twin-tunnels: Influence of the relative position and construction procedure. Tunnelling and Underground Space Technology, 23 (2), 210, 2008.

3. JINXING L., DEQIANG Y., ZHIHUA F., JUNLING Q., HAOBO F. Mechanical Characteristics of a Multi-Arch Tunnel Support Structure in Loess. Modern Tunnelling Technology, 54 (5), 5180, 2017.

4. XINTONG W., SHUCAI L., XIUYUAN M., YIGUO X., JIE H., ZHIQIANG L. Risk Assessment of Rockfall Hazards in a Tunnel Portal Section Based on Normal Cloud Model. Polish Journal of Environmental Studies, 26 (5), 2295, 2017.

5. YINGCHAO W., GUNEY C. O., LINBING W., BO M. Risk Assessment of Water Inrush in Karst Tunnels Based on the Ideal Point Method. Polish Journal of Environmental Studies, 28(2), 901, 2019.

6. ZIYONG C. Study on mechanical behavior and interaction of shallow buried large section tunnel with small net distance; Hunan University of Science and Technology: Xiangtan, China, 27, 2016.

7. MINGFENG L., DAYONG L., WEICHAO Y., CHENGHUA S., LIMIN P., JUAN H. Model test to investigate failure mechanism and loading characteristics of shallow-bias tunnels with small clear distance. Journal of Central South University, 23 (12), 3312, 2016.

8. JAMSHID G., RANDALL E. Interaction between two parallel tunnels. International Journal for Numerical and Analytical Methods in Geomechanics, 1 (1), 75, 1977.

9. HARVEY B., KIM S., MILLIGAN G.W.E. Model testing of closely spaced tunnels in clay. Geotechnique, 48 (3), 375, 1998.

10. HEFNY A.M., CHUA H.C., JIYUN Z. Parametric Studies on the Interaction between Existing and New Bored Tunnels. Tunnelling and Underground Space Technology, 19 (4-5), 471, 2018.

11. JINYANG F., JUNSHENG Y., YAN L., SYED M.A. An analytical solution for deforming twin-parallel tunnels in an elastic half plane. International Journal for Numerical and Analytical Methods in Geomechanics, 39 (5), 524, 2014. 
12. NGOC A. D., DANIEL D., PIERPAOLO O. 3D numerical investigation on the interaction between mechanized twin tunnels in soft ground. Environmental Earth Sciences, 73 (5), 2101, 2015.

13. NGOC A. D., DANIEL D., PIERPAOLO O. 3D numerical investigation of mechanized twin tunnels in soft ground Influence of lagging distance between two tunnel faces. Engineering Structures, 109 ,117, 2016.

14. WENGANG Z., ANTHONY G. Predictive models of ultimate and serviceability performances for underground twin caverns. Geomechanics and Engineering, 10 (2), 175, 2016.

15. FAISAL I.S. Interaction of Twin Circular Shallow Tunnels in Soils-Parametric Study. Open Journal of Civil Engineering, 7 (1), 100, 2017.

16. XIANG L., QIAN F., DINGLI Z. Mechanical responses of existing tunnel due to new tunnelling below without clearance. Mechanical Responses of Existing Tunnel Due to New Tunnelling Below Without Clearance, 80, 44, 2018.
17. YONG Y., CHUAN H., ZHUOXIONG X. Study of mechanical behavior and reinforcing measures of middle rock wall of parallel tunnel with small interval. Rock and Soil Mechanics, 28 (9), 1883, 2007.

18. GENGFENG W., XIAOHUI X., YONGXING Z., GUILIN W. Comparative Study of Rational Excavation Method and Support Parameter for Large-span Small-spacing Tunnel. Journal of Highway and Transportation Research and Development, 28 (3), 101, 2011.

19. DONGLIANG Z., JINFENG Z. Safe thickness of floor of forked tunnel in karst areas. Journal of Central South University (science and Technology), 46 (5), 1886, 2015.

20. SHUCAI L., HANPENG W., XUEFEN Z.: Forked Tunnel Stability Analysis and Its Construction Optimization Research. Chinese Journal of Rock Mechanics and Engineering, 27 (3), 447, 2008.

21. JIANWU G. Study on construction mechanical behavior of highway tunnel with large section and small spacing; Tongji University: Shanghai, 23, 2008. 